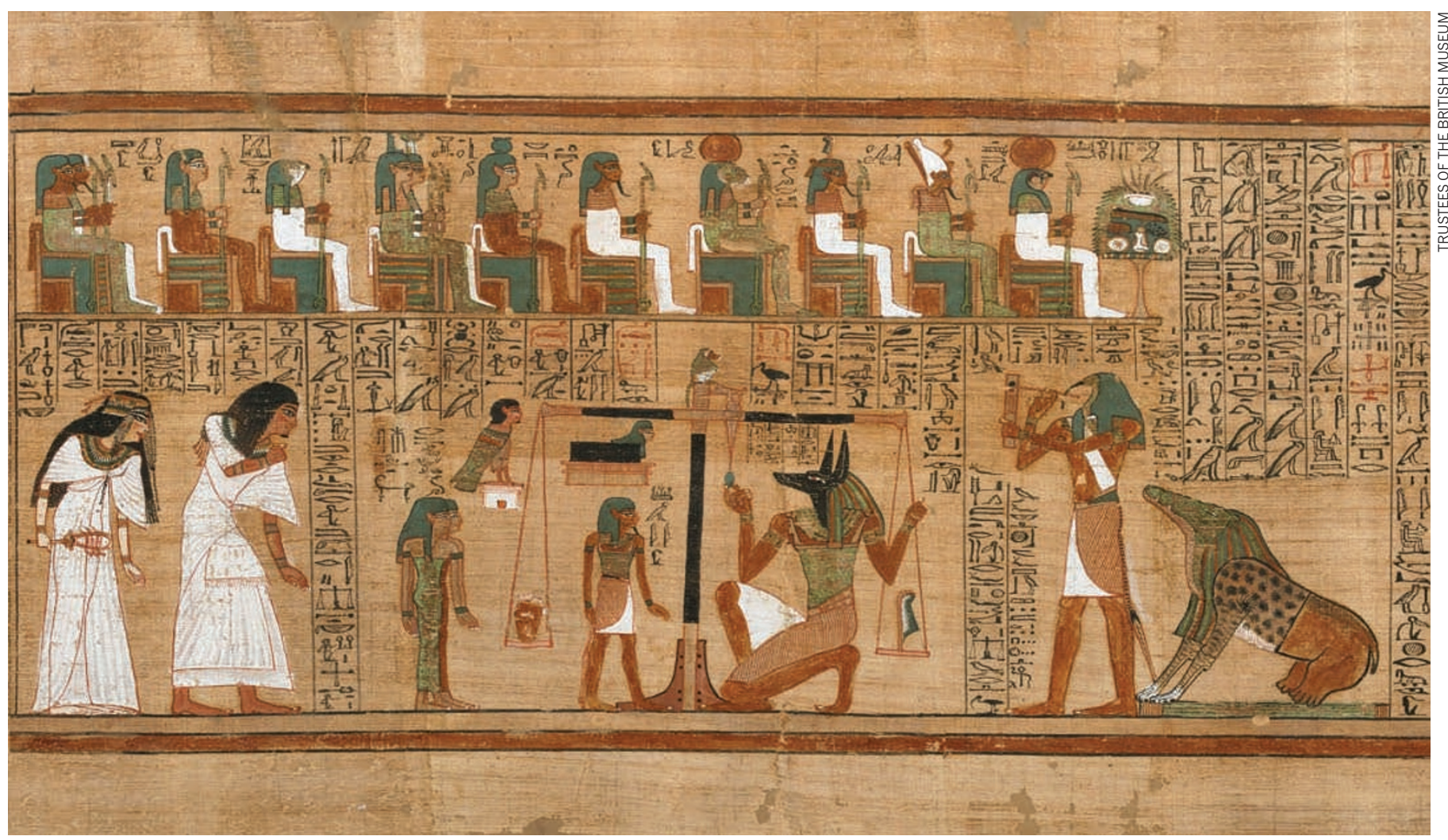

Ancient Egyptians believed that their lives would be judged by the gods when they died — as shown in the papyrus of Ani, part of a Book of the Dead from 1275 BC.

HISTORY

\title{
How to behave beyond the grave
}

\section{Instructions for the afterlife from Ancient Egypt reveal a step change in moral psychology, discovers Andrew Robinson.}

$\mathrm{I}$ n 1819, the English physician and polymath Thomas Young - known for his discovery of the interference of light - published a pioneering article on ancient Egypt in the Encyclopaedia Britannica. It offered a partially correct translation of the Rosetta Stone's hieroglyphic and demotic texts and outlined the new science of Egyptology. Young persevered in trying to understand the scripts, expressing impatience with the "monstrously complicated Egyptian superstitions". But he was overtaken. His reluctance to engage with the bewildering pantheon of animal-headed Egyptian gods and priestly mumbo-jumbo was a key factor in the ascendance of his French rival, the philologist Jean-François Champollion, who deciphered the Egyptian hieroglyphic script fully in 1822-23.

Visitors to Journey Through the Afterlife, the British Museum's elegant exhibition on the ancient Egyptian Book of the Dead, may initially sympathize with Young. The displayed texts - not a single book but various compilations of instructions for the afterlife, in hieroglyphic, hieratic and demotic scripts describe a bizarre universe of belief. They were first interpreted as a funerary ritual by Champollion

Journey Through the Afterlife: Ancient Egyptian Book of the Dead British Museum,

London.

Until 6 March 2011. working from papyrus scrolls in the 1820s.

Yet the intricately painted vignettes featuring the deities, animals, chimeras, kings and scribes of Egypt more than 3,000 years ago - have a disconcerting power. However fantastical the ideas depicted, the Book's pages document the shift in human thought towards judgements based on moral behaviour. Ethical precepts were written down in Egypt as early as 3000 вс. They were followed more than a thousand years later by the Babylonian King Hammurabi's famous law code.

The Book of the Dead, which appeared before the beginning of the New Kingdom around $1550 \mathrm{BC}$ and was commonly used until the Graeco-Roman era in Egypt in the first century $\mathrm{BC}$, shows for the first time the idea that the benefits of eternal life depend on an individual's adherence to correct behaviour on Earth. The law of ancient Israel, and the Ten Commandments in the Bible, were influenced by ancient Egyptian ethics.

Inscribed on stone sarcophagi, wooden coffins and stone amulets, but mainly painted and drawn on long papyrus scrolls placed close to a mummified corpse, Books of the Dead collected up to 200 spells. They were intended to reanimate and protect the corpse of an Egyptian in the afterlife, in a civilization where the average lifespan was 35 years. Neither the number of spells nor their order and content were fixed, so there is no definitive version of the Book; nor does it have a simple narrative, although the exhibition does its best to provide one.

The dominant idea is that the $b a$ (soul) of the deceased should fly during the daylight hours from the grave of its mummified
9 NATURE.COM For an exhibition on ancient Egyptian body image, see: go.nature.com/lebtdl 
corpse and continue to enjoy earthly pleasures beside the fertile Nile, returning at nightfall - much as the Sun god Ra endlessly cycles through the sky. Indeed, the ancient Egyptians called these compilations the 'book of coming forth by day'; the modern name 'book of the dead' was coined by the German Egyptologist Richard Lepsius in the 1840s, probably from the term used by Egyptian workers on excavations when they discovered such manuscripts.

There are major collections of Books of the Dead in museums in Egypt, Europe and the United States. The British Museum's holding is among the finest, and this exhibition is drawn almost exclusively from it. Many of the papyri have not been exhibited before, mainly because of the extreme sensitivity to daylight of the paints used in illustrating them. Tests by British Museum conservationists on the pigments, such as realgar (red arsenic) and orpiment (yellow arsenic), show that fading begins within days of exposure to natural light. "Choosing items which could be exhibited safely has been a lengthy process", writes the exhibition's curator John H. Taylor in the magnificent catalogue. Moreover, sensitivity of the paints to vibration means that the museum will have to modify its original plan of taking the exhibition on tour.

The best-known vignette in the Book of the Dead, rightly given pride of place near the end of the exhibition, is the judgement of the deceased before he or she is permitted to enter the afterlife. In the papyrus of Ani (pictured), a scribe who probably died around $1275 \mathrm{BC}$ during the reign of Ramesses II, Ani and his wife bow respectfully towards the gods, as Ani's heart (regarded as the seat of intelligence) is weighed in the balance scales by the jackal-headed Anubis against the feather of Maat (truth). The procedure is watched greedily by Ammit the Devourer, a monstrous combination of crocodile, lion and hippopotamus.

Ani speaks to his heart, telling it not to testify against him like a bad conscience. "The Egyptians devised ways to escape punishment by the gods, but the fact that they felt a need to do so is revealing of a new stage in human psychology, a new notion of just behaviour," notes Neil MacGregor, director of the British Museum. On studying this compelling vignette, even visitors as dismissive of Egyptian mysticism as Young would have to agree.

Andrew Robinson is a writer based in London. He is writing a biography of Jean-François Champollion. e-mail:ar471@cam.ac.uk

TECHNOLOGY

\section{Libraries of the future}

\section{A hands-on exhibition shows how online tools are shaping the way we use knowledge, says Aleks Krotoski.}

$\mathrm{T}$ The changing role of the library in scientific enquiry is explored in Growing Knowledge, an interactive exhibition at the British Library in London. Through hands-on demonstrations of the latest digital technologies - including the European premiere of Sony's $360^{\circ}$ autostereoscopic (three-dimensional) display - the curators hope to stimulate scientists to pursue new questions, techniques and forms of collaboration.

Visitors can try out immersive video and input technologies and interact with online research tools on multiscreen workstations. Touch screens demonstrate ways in which high-resolution images of scientific phenomena, ancient texts or sculptures can be stored, shared and manipulated by collaborators worldwide. Topics of debate are emphasised on displays and video panels, through interviews with developers, academics "Manyscientists and information are concerned scientists. that publicly posted content that has not been peer reviewed could be used out of context."

The exhibition also highlights the recent shift towards open data sets. Databases are increasingly being made freely available to the research community as a means of maximizing efforts and inspiring more creative analyses. Public release of scientific data is often demanded by research-funding bodies, but concerns remain about data ownership and misrepresentation. To alleviate such fears, the curators display a range of examples of such data sets, including the website that collects public information from the UK government (http://data. gov.uk), orchestrated by Tim Berners-Lee, inventor of the World Wide Web, and computer scientist Nigel Shadbolt of the University of Southampton, UK.

Issues around data sharing are explored in related workshops. Questions to be investigated include how the academic community ensures that author contributions are acknowledged; how shared data are secured and protected in a way that does not conflict with accessibility goals; and how the information is archived. Others look at how researchers with access to different technology platforms can work
Growing

Knowledge:

The Evolution of

Research

British Library, London.

Until 16 July 2011.

will be reported as
authors seek to distribute findings to as wide an audience as possible. Funding bodies increasingly require digital dissemination of results to maximize public impact, and some researchers rush to reveal results on blogs to claim priority. Articles openly released on the Internet garner more citations than those in subscription journals, but many scientists are concerned that publicly posted content that has not been peer reviewed could be used out of context. Traditional forms of academic publication are still favoured, although other open-access models are being explored by publishers.

The exhibition also probes advances in searching for information. Future readers might require 'intelligent' personalized searches that deliver quality content based on previous patterns of search activity. Library users are also likely to participate in knowledge generation through shared resources such as Wikipedia or crowdsourced research projects such as Galaxy Zoo, which asks the public to help classify millions of galaxies. The challenge for libraries is to handle the data deluge - which is expected to increase exponentially - by exploiting remote, Internet-based 'cloud computing' storage.

Although solutions to managing information in the Internet era are still evolving, one thing is certain: library visitors of the future will be demanding. They will expect interactive catalogues to contain every permutation of possible data, and for it to be accessible on multiple devices at any time. Research libraries will define and maintain standards, host and disseminate archives and provide flexible user support. Library buildings will encourage collaboration and discussion as well as quiet study. Growing Knowledge exposes these changes at the core of research practice.

Aleks Krotoski is Researcher-in-Residence of the Growing Knowledge exhibition at the British Library, London.

e-mail:aleks@alekskrotoski.com 